\title{
Evaluation of performance of POAMA forecast system in predicting monthly precipitation over Indonesia
}

\author{
Suaydhi* \\ Center for Atmospheric Science and Technology (PSTA), LAPAN, \\ JI. Dr. Junjunan 133, Bandung 40173, Indonesia
}

\begin{abstract}
Hindcast produced by a model used in a numerical model-based seasonal prediction system is an essential part in the operational seasonal prediction system. This paper is aimed at evaluating the performance of POAMA model from the climatological aspect. The data used in this research are obtained from three variants of POAMA m24 model. The results show that the annual cycle of climatological rainfall averaged over Indonesia is well simulated by POAMA m24, although there is a dry bias in the rainy season and a wet bias in the dry season. From those three variants, $\mathrm{m} 24 \mathrm{~b}$ model has a relatively low variation of bias against lead-time compared with the $\mathrm{m} 24 \mathrm{a}$ and $\mathrm{m} 24 \mathrm{c}$ models due to the implementation of flux correction scheme in m24b model. However, the performance of POAMA m24 model with a resolution of T24 is inferior to CFSv2 with a resolution of T126 in simulating the spatial pattern of rainfall over Indonesia. Beside model resolution, convection scheme used in a model also has significant influence. This can be seen from the resemblance between the spatial pattern of total rainfall and that of convective rainfall. Thus, the horizontal resolution of a model and a suitable convection scheme for Indonesian region are the two factors that must form important consideration in the development of Indonesian seasonal prediction system.
\end{abstract}

Keywords: hindcast, Indonesia, POAMA, seasonal prediction

Received: August 6, 2017; Accepted: September 12, 2017; Published online: October 31, 2017

*Corresponding author: suaydhi@lapan.go.id

Citation: Suaydhi (2017). Evaluation of performance of POAMA forecast system in predicting monthly precipitation over Indonesia. Journal of Science and Science Education, 1(2), 45-53.

\section{Introduction}

Seasonal prediction is an effort to provide information about atmospheric condition, especially air temperature and precipitation, on a seasonal scale or several months ahead. The ability of numerical/dynamical models in predicting season have increased greatly since the development of data assimilation system in the 1990s. Dynamical seasonal prediction system began operational in the United States in 1995 under the name of NMC MRF (National Meteorological Center Medium Range Forecast). This operational forecast system is now known as NCEP CFSv2 (National Center for Environmental Prediction Climate Forecast System version 2; Saha et al., 2010). In Europe, seasonal climate prediction is developed by ECMWF (European Centre for Medium-Range Weather Forecast) since 1996 which was then known as System-1, and now become ENSEMBLES (Weisheimer et al., 2009). In Australia, POAMA (Predictive Ocean Atmosphere Model for Australia; Hudson et al., 2013) is the operational seasonal prediction system. This system was established in 2002. All the operational seasonal prediction systems in those countries were developed through intensive research over the years. 
In principle, the numerically-based seasonal prediction system should give better seasonal prediction than the statistically-based. This is because numerical models represent the dynamics of atmosphere, ocean, and land surface, so that they have the ability to handle various linear and nonlinear interactions and also have the potential resilience against climate change. Results from van Oldenborgh et al. (2005) show that numerically-based seasonal prediction system is superior in predicting the start and amplitude of the 1997-1998 El Nino during spring and summer, while the statistical model is better in predicting the evolution of the El Nino during autumn and winter. However, the ability of the numerical model in producing long-term prediction is limited by model error (Palmer et al., 2012).

The seasonal precipitation over Indonesia is strongly associated with monsoon reversal flow. The prediction of seasonal and monthly precipitation is very important for the agriculture and economy of Indonesia. However, Indonesia does not have a numerically-based operational seasonal prediction system. The pragmatic way to develop such a system is to adopt one of the established global seasonal forecast systems in the world, e.g. CFSv2 from NCEP or POAMA from the Australian BoM. The performance of a prediction system must be evaluated before being used operationally in a country/region. This is conducted by verifying the results of hindcast (retrospective forecast) of such a system. Zhang et al. (2016) has evaluated the hindcasts of CFSv2 over the Indonesian region. Therefore, this paper is aimed at evaluating the performance of POAMA in predicting monthly prediction over the Indonesian region.

\section{Model and Data}

POAMA is a seasonal prediction system developed by the Australian BoM and CSIRO Marine Research. POAMA m2.4 is the latest operational model used by BoM for its seasonal prediction. POAMA m2.4 consists of coupled models of atmosphere/ocean/land surface and data assimilation system of atmosphere/ocean/land observations. The atmosphere model used in POAMA m2.4 is BAM version 3.0 with a horizontal resolution of T47 ( $250 \mathrm{~km})$ and 17 vertical levels, initialized by using ALI scheme (Hudson et al., 2011). The ocean model is ACOM version 2 with a horizontal resolution of $200 \mathrm{~km} \times 100 \mathrm{~km}$ and 25 vertical levels (Oke et al., 2005), initialized by using PEODAS (Yin et al., 2011). POAMA m2.4 prediction system is initialized every 10 days on the $1^{\text {st }}, 11^{\text {th }}$, and $21^{\text {st }}$ day every month. The system initialized on the $1^{\text {st }}$ day generates forecast for the same month, but the ones initialized on the $11^{\text {th }}$ and $21^{\text {st }}$ day produce forecasts for the subsequent month.

POAMA m2.4 model has three variants, i.e. $\mathrm{m} 2.4 \mathrm{a}, \mathrm{m} 2.4 \mathrm{~b}$, and $\mathrm{m} 2.4 \mathrm{c}$. The first two variants use newer atmospheric model with better physics than $\mathrm{m} 2.4 \mathrm{c}$ in its shallow convection. The $\mathrm{m} 2.4 \mathrm{~b}$ implements flux correction scheme to reduce bias in the model climatology arising from longer forecast lead-time, while m2.4a does not implement that scheme (Schepen et al., 2014). Each variant has 11 ensemble members of forecast results. Hence there are a total of 33 ensemble members in POAMA seasonal prediction system. The outputs of POAMA hindcasts are available from January 1981 until December 2010. In this paper, monthly climatological data from each variant is used to evaluate POAMA model performance in predicting season in Indonesia.

Three sources of data are used to verify the results of POAMA hindcasts. First is monthly rainfall data from the Climate Prediction Center (CPC) Merged Analysis of Precipitation (CMAP; Xie \& Arkin, 1997). These data are available from 1979 until now with a resolution of $2.5^{\circ}$ same as that of POAMA data. Second is the convective rainfall data from Tropical Rainfall Measuring Mission (TRMM; Iguchi et al., 2000) 3A25 products. Lastly is the wind and temperature data from the 
European Centre for Medium-range Weather Forecasts (ECMWF) Reanalysis (ERA) Interim (Dee et al., 2011).

\section{Results and Discussion}

The comparison of monthly average of Indonesia rainfall between observation and hindcast results is shown in Figure 1. The left panel of Figure 1 indicates that the POAMA seasonal prediction system with zero month lead time is able to simulate the annual cycle of rainfall over Indonesia fairly well. Although POAMA model could simulate heavy rainfall during rainy season and light rainfall during dry season, it has a dry bias during rainy season and a wet bias during a dry season for total rainfall (black line against blue line). For convective rainfall, the POAMA hindcast (red line) is slightly higher than the observed convective rainfall from TRMM (green line). The $\mathrm{m} 2.4 \mathrm{~b}$ seems to have higher bias from April to August than those of $\mathrm{m} 2.4 \mathrm{a}$ and $\mathrm{m} 2.4 \mathrm{c}$ models. Similar feature is also observed in the convective rainfall. This indicates that the convective scheme plays an important role in numerical models in simulating rainfall over Indonesia.
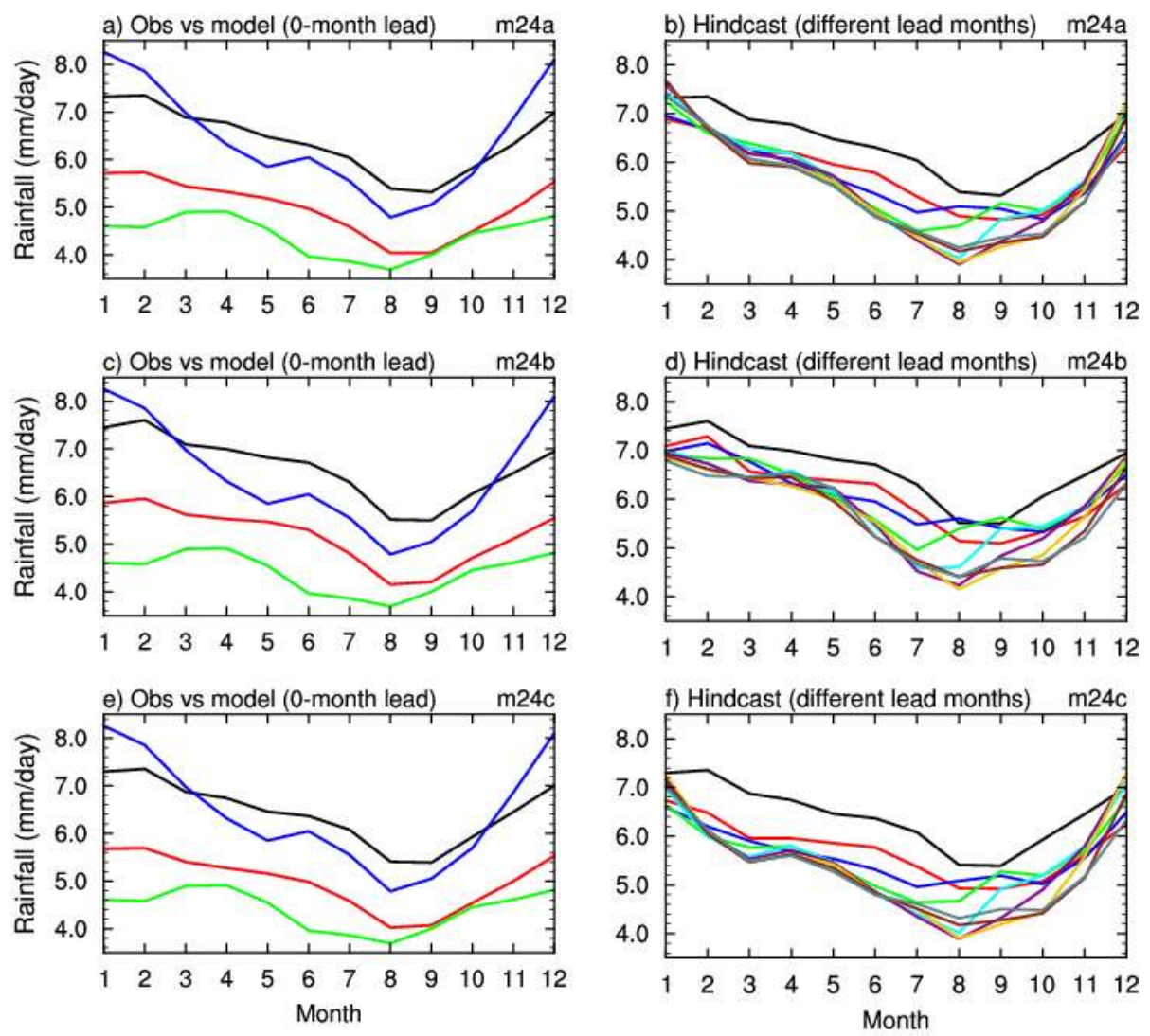

- Hindcast (Total) - Hindcast (Conv) • CMAP - TRMM (Conv) $\bullet 0 \cdot 1 \cdot 2 \bullet 3 \bullet 4 \bullet 5 \bullet 6 \bullet 7 \bullet 8$

Figure 1. Comparison of annual cycles of rainfall between POAMA hindcats and observations (CMAP and TRMM).

The right panel of Figure 1 shows monthly average rainfall over Indonesia from different lead times of POAMA hindcasts (0-8 month lead time). It shows that rainfall prediction during dry season (July-September) is more random than those of other months. This indicates that rainfall prediction during dry season is much sensitive to the initial condition than the prediction for the rainy season. The reason is the prediction for dry season uses initial conditions from boreal spring and early summer where the ocean and atmosphere conditions vary greatly against time. This figure also 
Suaydhi: Evaluation of performance of POAMA forecast system in predicting monthly precipitation over Indonesia

shows that $\mathrm{m} 2.4 \mathrm{~b}$ model has less variation of hindcasts against lead-time than those of the other two models. The results prove that flux correction scheme implemented in $\mathrm{m} 2.4 \mathrm{~b}$ to reduce bias against lead time functions as intended (Schepen et al., 2014).

Figure 2 shows the comparison between the observed and the zero-month lead time simulated rainfall climatology from POAMA during the dry season. The red box on that figure is the domain used in averaging the results shown in Figure $1\left(15^{\circ} \mathrm{S}-10^{\circ} \mathrm{N}, 95^{\circ}-145^{\circ} \mathrm{E}\right)$. During the dry season, CMAP data show that the rainfall peak spans from west to east over the northern part of Indonesia and from south to north over the Indian Ocean off the west coast of Sumatra until the Bengal Bay (Figure 2a). Meanwhile, the southern part of Indonesia receives little rainfall. The hindcast results from the three models of POAMA are able to reproduce rainfall patterns during the dry season, but with much higher intensity in the rainfall peak area to the north of Indonesia than the observations. The three models also simulate much higher rainfall than the observations over the west coast of Sumatra, upper part of Sulawesi, and over Papua (Figure $2 b-d$ ). The wet bias over Papua is also simulated by CFSv2 model (Zhang et al., 2016).

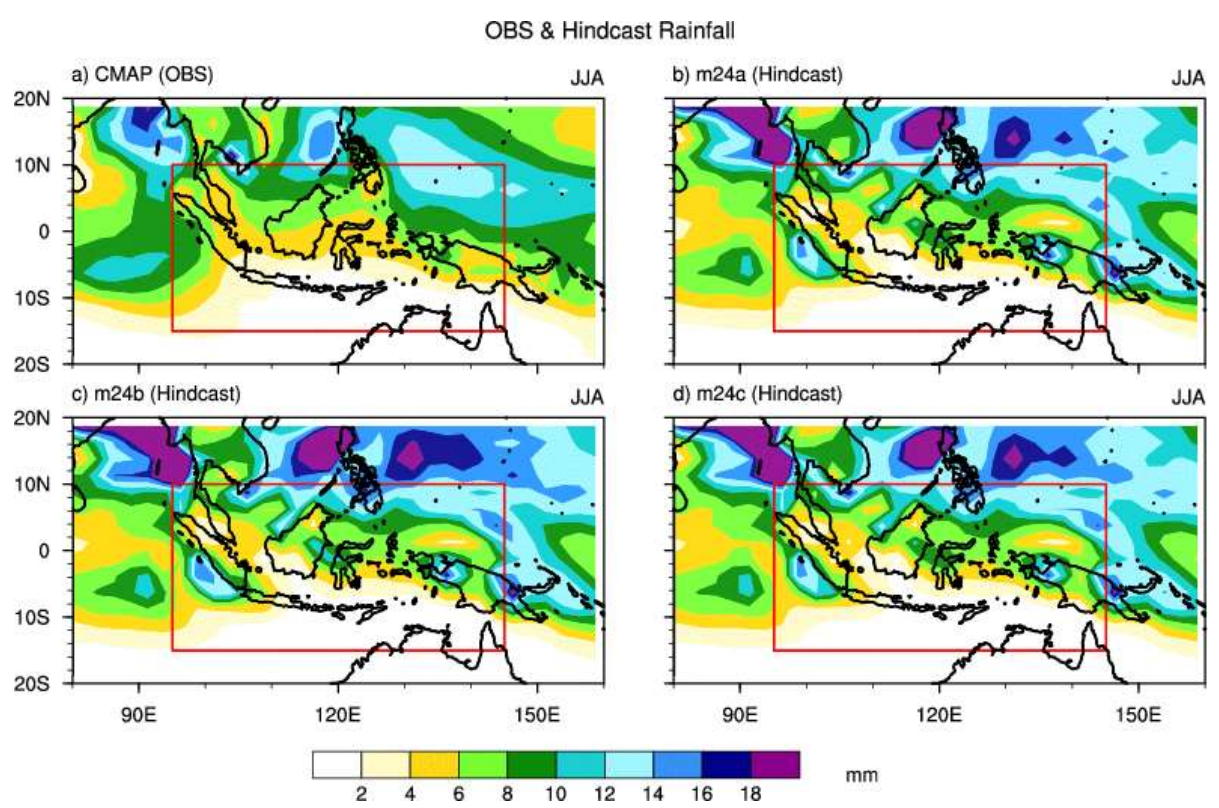

Figure 2. Comparison of rainfall between observation (CMAP) and hindcast results of POAMA during dry season.

Figure 3 is similar to Figure 2, but for the rainy season. The CMAP data show that there are three rainfall centers over Indonesia during the rainy season, i.e. off the west coast of Sumatra, off the south-west coast of Sulawesi, and over Arafura Sea (Figure 3a). The hindcast results from the three variants of POAMA are able to reproduce rainfall centre off the west coast of Sumatra and over Java. However, the models simulate much lower rainfall over Karimata Strait, off the south-west coast of Sulawesi, and off the south coast of Papua. The models overestimate rainfall between Kalimantan and Sulawesi, southern Maluku, and over Papua (Figure 3b-d). The hindcast results from POAMA in simulating rainfall pattern during rainy season are inferior to those of CFSv2. This is probably due to the higher resolution of CFSv2, i.e. T126 (Zhang et al., 2016), compared to T47 of POAMA (Schepen et al., 2014). 


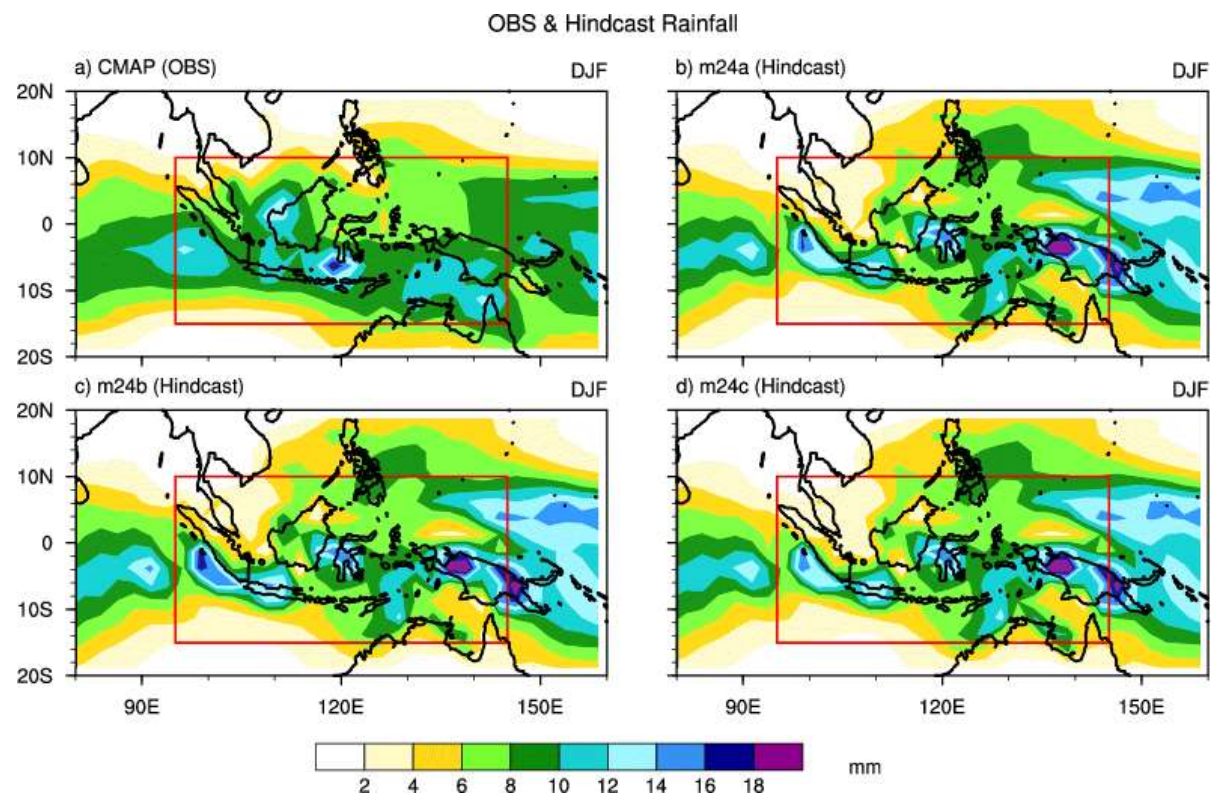

Figure 3. Same as Figure 2, except for the wet season.

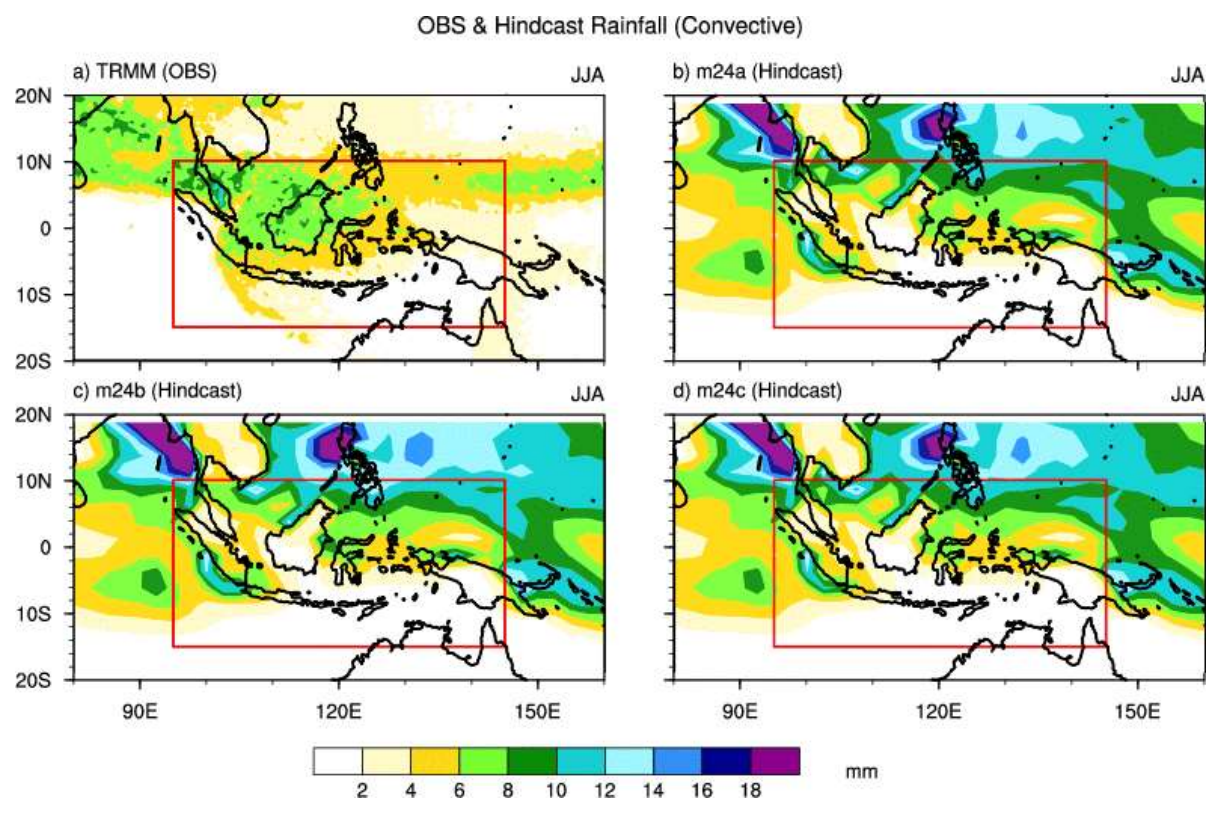

Figure 4. Same as Figure 2, except for convective rainfall from TRMM and POAMA.

To see the influence of the convective rainfall on rainfall pattern over Indonesia, convective rainfall from POAMA hindcast is compared with that of TRMM satellite (Figures 4 and 5). The peak of convective rainfall from TRMM is seen over Kalimantan, Karimata Strait, South China Sea, Sulawesi Sea, and Bengal Bay (Figure 4a). The POAMA models could only to simulate convective rainfall centre over the Bengal Bay. Other convective rainfall centers produced by the models over the west coast of Sumatra and to the north of the Philippines. The models also simulates too much convective rainfall over the Pacific Ocean east of the Philippines (Figure $4 b-d$ ). The pattern of convective rainfall is similar to that of total rainfall, except over Papua. 
Figure 5 show the comparison of convective rainfall between TRMM and POAMA hindcasts during rainy season. A relatively high convective rainfall is observed over the southern part of Indonesia, except over Papua and Arafura Sea (Figure 5a). The POAMA hindcasts are only able to simulate convective rainfall over Java, and from Java Sea to Banda Sea. The models simulate very much lower convective rainfall over Sumatra, Kalimantan, and Karimata Strait than the observed. On the other hand, they overestimate convective rainfall off the west coast of Sumatra, over Sulawesi and its surrounding, Banda Sea, and east of Papua (Figure 5b-d). Similar to that of the dry season, the convective rainfall spatial pattern over Papua is also different from the total rainfall pattern during rainy season.

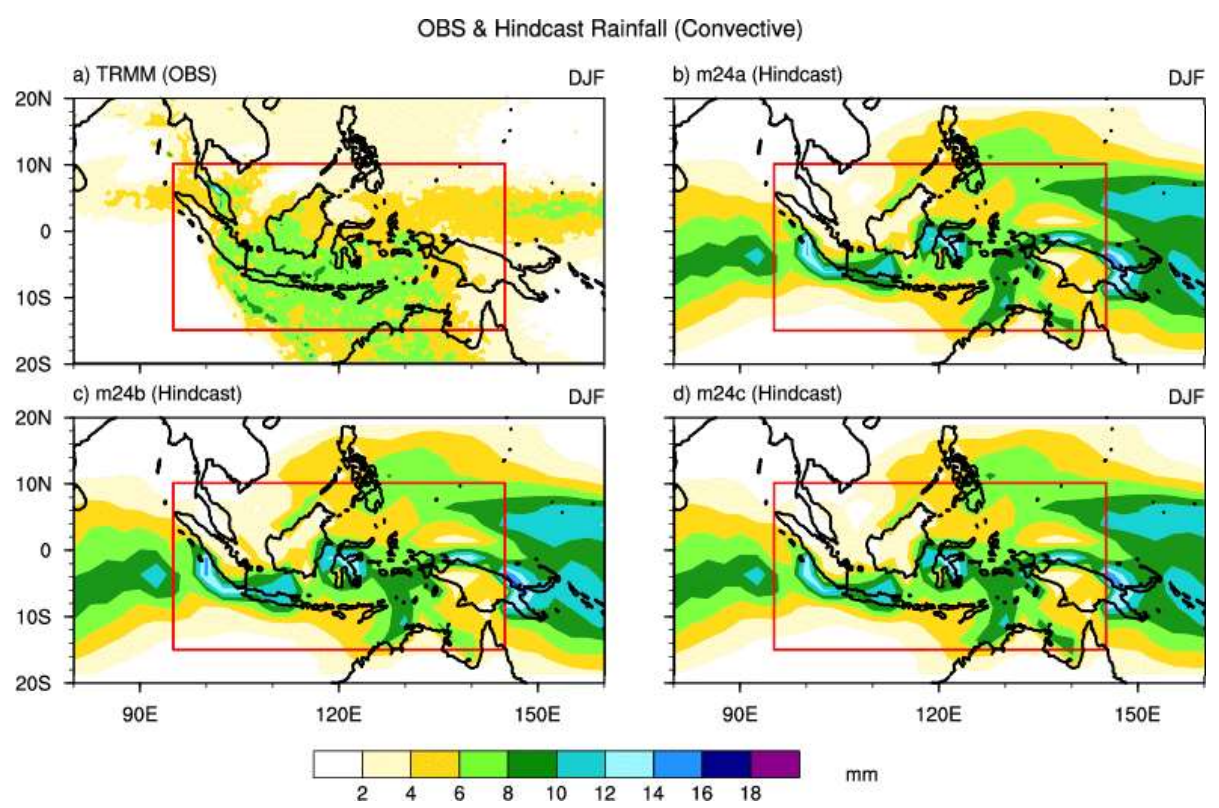

Figure 5. Same as Fig. 4, except for rainy season.

The spatial pattern of horizontal wind and air temperature at $850 \mathrm{hPa}$ level during dry season is shown in Figure 6. During this period, the southern hemisphere is in winter season, so that the wind flows from Australia towards Indonesia. The observation shows that horizontal wind at $850 \mathrm{hPa}$ level over the big islands of Indonesia (Sumatra, Kalimantan, Sulawesi, and Papua) undergoes inhibition from tall mountains over those islands (Figure 6a). The wind coming from the Indian Ocean is blocked by Bukit Barisan mountain range, so a rainfall center is formed off the west coast of Sumatra (see Figure 2a). The wind flowing towards Kalimantan, Sulawesi, and Papua is blocked by mountains in Sulawesi and in Papua respectively. Consequently, there are no rainfall centers observed over those three islands (see Figure 2a).

Models with low horizontal resolution such as POAMA usually have poor representation of the orography. Therefore, the $850 \mathrm{hPa}$ level wind is properly simulated by POAMA models. The wind from hindcast results seems to pass through the mountains without inhibition (Figure 6b-d). As a result, rainfall centers are formed where the wind converges, such as off the west coast of Sumatra and above the "bird head" of Papua (Figure $2 \mathrm{~b}-\mathrm{d}$ ). The observed air temperature at $850 \mathrm{hPa}$ level over Indonesia is relatively higher than that of the simulation (Figure 6b-d). Vertical profile of air temperature has significant effect on convection system simulated by a model. 
OBS \& Hindcast Wind $850 \mathrm{mb}$

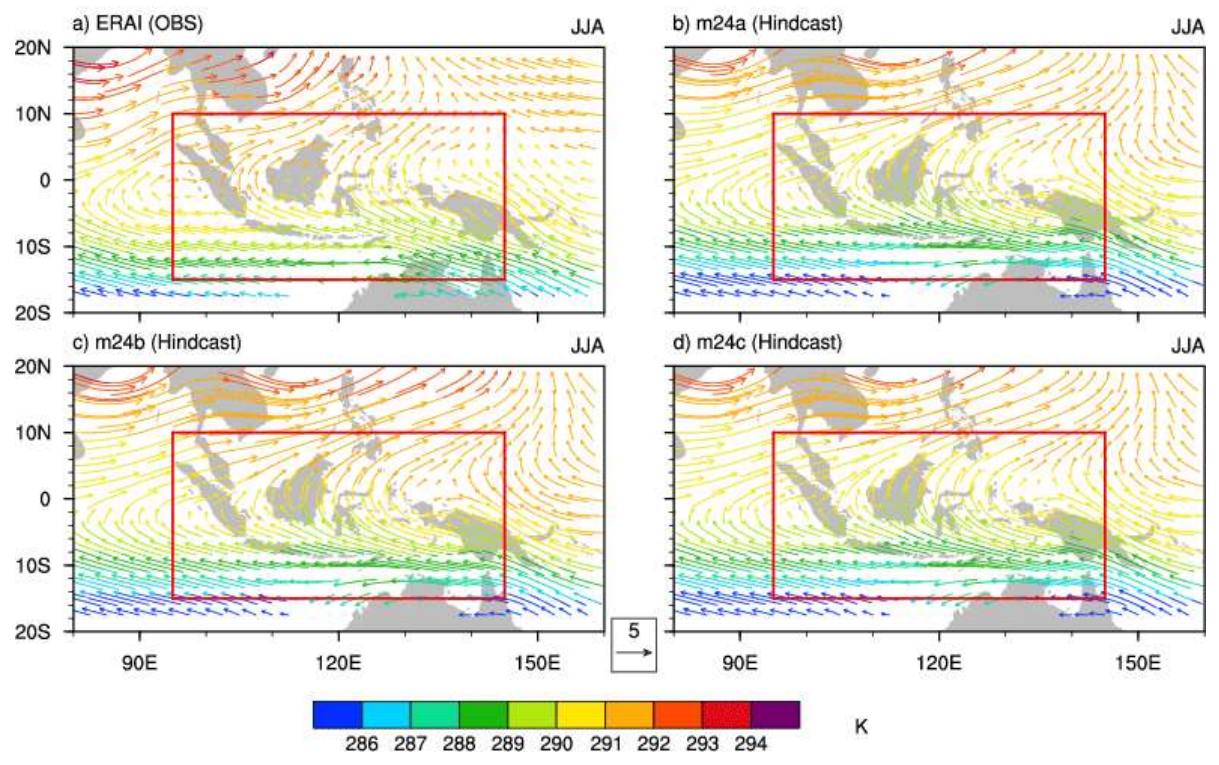

Figure 6. Wind and air temperature at $850 \mathrm{hPa}$ level between observations (ERA Interim) and hindcast results from POAMA for the dry season.

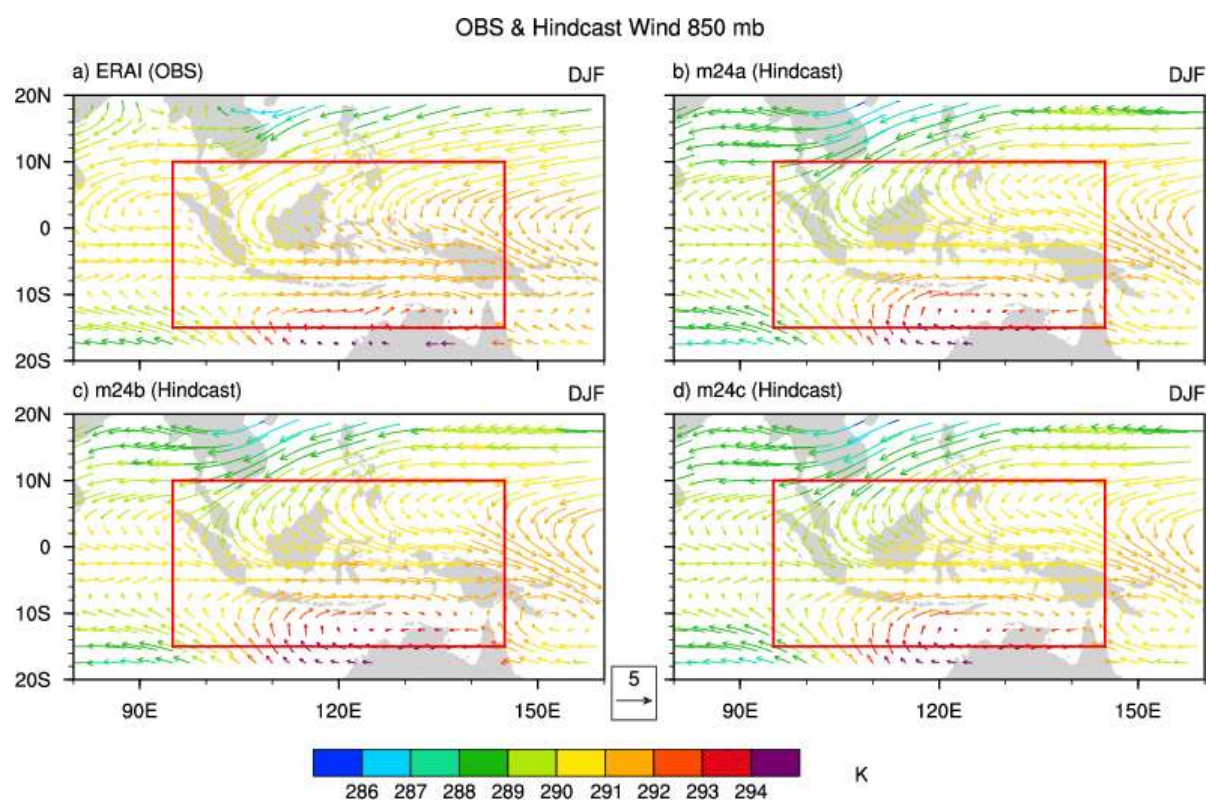

Figure 7. Same as Fig. 6, except for rainy season.

Orography effects can be clearly seen during the rainy season, when the $850 \mathrm{hPa}$ level wind flows from the Pacific and Indian Oceans towards Indonesia (Figure 7). The ERA Interim data (Figure 7a) show that wind flowing over the Java Sea all the way to the Arafura Sea is dominated by wind from the South China Sea, in contrast to the model results (Figure 7b-d) which show the wind is originated from Indian Ocean. The observation shows that the wind from the South China Sea is able to reach the mainland of Sumatra causing heavy rainfall over this area (Figure 3a). Meanwhile, the simulated wind from the South China Sea seems to be pushed eastward bypassing Kalimantan and the rainfall center is formed over Central Sulawesi. As a consequence, the simulated rainfall over Sumatra is less rainfall than observed during rainy season (Figure $3 b-d$ ). On the ERA Interim 
data, little vortex is formed over the Carpentaria Bay (Australia) which causes rainfall center formed over southern Papua. In the hindcast results, this center is formed a little bit to the west.

\section{Conclusion and Remarks}

Hindcast or retrospective prediction is an important part of seasonal prediction system. Hindcast results are used for calculating the anomaly of seasonal prediction results. This paper shows that annual cycle of average rainfall over Indonesia is simulated fairly well by the POAMA model, similar to that obtained by Zhang et al. (2016) for CFSv2. However, the spatial pattern of rainfall from CFSv2 is superior to that demonstrated by POAMA m2.4, both during dry and rainy seasons. It seems that model resolution causes this difference, since CFSv2 has much horizontal resolution at T126 and POAMA m2.4 has only a resolution of T47.

POAMA seasonal prediction system uses three model variants ( $\mathrm{m} 2.4 \mathrm{a}, \mathrm{m} 2.4 \mathrm{~b}$, and $\mathrm{m} 2.4 \mathrm{c}$ ). The $\mathrm{m} 2.4 \mathrm{~b}$ model which implements flux correction scheme reproduces less bias on longer lead time compared to the other two models. Nevertheless the simulation of the convective rainfall is not satisfactory. This evaluation will be used as a base for developing seasonal prediction over Indonesia, for example by downscaling the POAMA seasonal prediction outputs to obtain higher resolution seasonal prediction data that can be useful for agricultural sector.

\section{Acknowledgment}

The author thanks the Australian Bureau of Meteorology who give permission to use their data of POAMA hindcast results for this research.

\section{References}

Dee, D. P., Uppala, S. M., Simmons, A. J., Berrisford, P., Poli, P., Kobayashi, S., ... Vitart, F. (2011). The ERAInterim reanalysis: configuration and performance of the data assimilation system. Q. J. R. Meteorol. Soc., 137 (656), 553-597. https://doi.org/10.1002/qj.828

Hudson, D., Alves, O. , Hendon, H. H., \& Wang, G. (2011). The impact of atmospheric initialisation on seasonal prediction of tropical Pacific SST. Clim. Dyn., 36(5-6), 1155-1171. https://doi.org/10.1007/s00382-0100763-9

Hudson, D., Marshall, A. G. , Yin, Y., Alves, O., \& Hendon, H. H. (2013). Improving intraseasonal prediction with a new ensemble generation strategy. Mon. Weather Rev., 141(12), 4429-4449. https://doi.org/10.1175/MWR-D-13-00059.1

Iguchi, T., Kozu, T., Meneghini, R., Awaka, J., \& Okamoto, K. (2000). Rain-Profiling Algorithm for the TRMM Precipitation Radar. J. Appl. Meteorol., 39(12), 2038-2052. https://doi.org/10.1175/15200450(2001)040\%3C2038:RPAFTT\%3E2.0.CO;2

Oke, P. R., Schiller, A., Griffin, D. A., \& Brassington, G. B. (2005). Ensemble data assimilation for an eddyresolving ocean model of the Australian region. Q. J. R. Meteorol. Soc., 131(613), 3301-3311. https://doi.org/10.1256/qj.05.95

van Oldenborgh, G. J., Balmaseda, M. A., Ferranti, L., Stockdale, T. N., \& Anderson, D. L. T. (2005). Did the ECMWF seasonal forecast model outperform statistical ENSO forecast models over the last 15 years? J. Clim., 18(16), 3240-3249. https://doi.org/10.1175/JCLI3420.1 
Palmer, T. N., Doblas-Reyes, F. J., Hagedorn, R., Alessandri, A., Gualdi, S., Andersen, U., ... Thomson, M. C. (2004). Development of a European multimodel ensemble system for seasonal-to-interannual prediction (DEMETER). Bull. Am. Meteorol. Soc., 85(6), 853-872. https://doi.org/10.1175/BAMS-85-6853

Saha, S., Moorthi, S., Pan, H.-L., Wu, X., Wang, J., Nadiga, S., ... Goldberg, M. (2010). The NCEP Climate Forecast System Reanalysis. Bull. Am. Meteorol. Soc., 91(8), 1015-1057. https://doi.org/10.1175/2010BAMS3001.1

Schepen, A., Wang, Q. J., \& Robertson, D. E. (2014). Seasonal Forecasts of Australian Rainfall through Calibration and Bridging of Coupled GCM Outputs. Mon. Weather Rev., 142(5), 1758-1770. https://doi.org/10.1175/MWR-D-13-00248.1

Weisheimer, A., Doblas-Reyes, F. J., Palmer, T. N., Alessandri, A., Arribas, A., Déqué, M., ... Rogel, P. (2009). ENSEMBLES: A new multi-model ensemble for seasonal-to-annual predictions - Skill and progress beyond DEMETER in forecasting tropical Pacific SSTs. Geophys. Res. Lett., 36(21), 1-6. http://dx.doi.org/10.1029/2009GL040896

Xie, P., \& Arkin, P. A. (1997). Global Precipitation : A 17-Year Monthly Analysis Based on Gauge Observations , Satellite Estimates, and Numerical Model Outputs. Bull. Am. Meteorol. Soc., 79(11), 2539-2558. https://doi.org/10.1175/1520-0477(1997)078<2539:GPAYMA>2.0.CO;2

Yin, Y., Alves, O., \& Oke, P. R. (2011). An Ensemble Ocean Data Assimilation System for Seasonal Prediction. Mon. Weather Rev., 139(3), 786-808. https://doi.org/10.1175/2010MWR3419.1

Zhang, T., Yang, S., Jiang, X., \& Zhao, P. (2016). Seasonal-Interannual Variation and Prediction of Wet and Dry Season Rainfall over the Maritime Continent: Roles of ENSO and Monsoon Circulation. J. Clim., 29(10), 3675-3695. https://doi.org/10.1175/JCLI-D-15-0222.1 